\title{
$\mathrm{Ti}_{40} \mathrm{Zr}_{10} \mathrm{Cu}_{36} \mathrm{Pd}_{14}$ 비정질기지 복합재의 미세조직과 기계적 특성에 미치는 냉각속도의 영향
}

\author{
박선용 $^{1,2} \cdot$ 임가람 $^{1} \cdot$ 나영상 $^{1, *} \cdot$ 김승언 $^{1} \cdot$ 최윤석 $^{2}$ \\ ${ }^{1}$ 재료연구소 금속재료연구본부 \\ ${ }^{2}$ 부산대학교 재료공학과
}

\section{The Effects of Cooling Rate on the Microstructure and Mechanical Properties of $\mathrm{Ti}_{40} \mathrm{Zr}_{10} \mathrm{Cu}_{36} \mathbf{P d}_{14}$ Metallic Glass Matrix Composites}

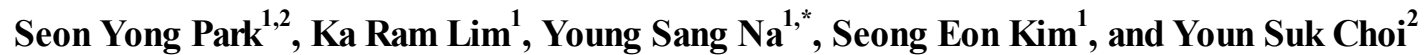 \\ ${ }^{1}$ Metallic Materials Division, Korea Institute of Materials Science, Changwon 51508, Republic of Korea \\ ${ }^{2}$ School of Materials Science and Engineering, Pusan National University, Busan 46241, Republic of Korea
}

\begin{abstract}
In this paper, we demonstrate that the microstructure and mechanical properties in the $\mathrm{Ti}_{40} \mathrm{Zr}_{10} \mathrm{Cu}_{36} \mathrm{Pd}_{14}$ alloy can be tailored by controlling the cooling rate during solidification. A lower cooling rate increases the volume fraction of crystalline phase such as B2 but decreases the free volume of the glassy matrix. The increase of the B2 volume fraction can dramatically enhance the toughness of the composites, since the B2 phase is relatively ductile compared to the glassy matrix and seems to have good interface stability with the matrix. From the experimental results, it was found that there is a transition point in the plasticity of the composites depending on the cooling rate. Here, we explain how the toughness of the composites varies in accordance with the cooling rate in the $\mathrm{Ti}_{40} \mathrm{Zr}_{10} \mathrm{Cu}_{36} \mathrm{Pd}_{14}$ alloy system.
\end{abstract}

(Received April 22, 2016; Accepted May 25, 2016)

Keywords: metallic glass matrix composite, cooling rate, B2 phase, microstructure, mechanical properties

\section{1. 서 론}

타이타늄계 비정질 합금은 밀도가 낮고 내식성 및 생체적 합성이 우수하여[1] 생체용 소재로서 잠재력이 크다. 현재까 지 Ti-Zr-Ni-Cu-Be-Nb [2], Ti-Ni-Cu-Sn [3], Ti-Cu-Ni-Co [4], Ti-Ni-Cu [5], Ti-Zr-Be-Cr [6], Ti-Cu-Ni-Al-Zr-Si-B[7], Ti-Ni-Cu-B-Si-Sn [8], Ti-Cu-Ni-Si-B [9], Ti-Zr-Cu-Ni [10] 등 다수의 타이타늄계 비정질 합금이 개발되어 보고된 바 있 다. 이들 합금 대부분은 공통적으로 인체에 독성을 갖는Ni 및 $\mathrm{Be}$ 등을 함유하고 있어 생체재료로 적용하기에는 부적합하 다. Inoue 그룹에서는 인체에 유해한 Ni 대신 Pd을 포함하는 $\mathrm{Ti}-\mathrm{Zr}-\mathrm{Cu}-\mathrm{Pd}$ 합금을 보고한 바 있으며 [11], 특히 $\mathrm{Ti}_{40} \mathrm{Zr}_{10} \mathrm{Cu}_{36} \mathrm{Pd}_{14}$ 합금은 비정질 형성능이 우수하여 최대 직 경 $6 \mathrm{~mm}$ 까지 비정질 시편 제조가 가능한 것으로 알려져 있 다. 하지만 비정질 단일상(monolithic metallic glass)으로 존

* Corresponding Author: Young Sang Na

[Tel: +82-55-280-3377, E-mail: nys1664@kims.re.kr]

Copyright (c) The Korean Institute of Metals and Materials
재할 경우에는 임계 하중이 가해질 때 전단 띠(shear band)의 급작스러운 전파를 막기 어려우므로 [12-14] 생체용 구조체 로서 적용하기에 어려움이 따른다. 비정질 기지에 연성을 갖 는 결정상을 포함하는 비정질 기지 복합재의 경우, 다중 (multiple) 전단 띠를 생성시키고 전단 띠의 전파를 지연시키 는 등 국부변형을 최소화함으로써 인성을 향상시킬 수 있어 구조용 소재로의 적용에 유리하다 [15,16]. 비정질 기지 복합 재를 구성하는 결정상의 분율은 합금의 화학조성 [17-25] 또 는 용탕의 냉각속도 [19]를 변화시키거나, 열처리 [26] 등을 통해서 얻어질 수 있다. 지금까지 비정질 기지 복합재에 관한 연구는 주로 합금의 화학조성을 변수로 하여 결정상의 분율 을 제어하는 경우가 많았다. 하지만 생체재료의 경우 합금의 조성이 변화하게 되면 새로이 임상시험(clinical test)을 거쳐 야 하기 때문에 이에 따른 비용이 많이 요구될 수 있다. 따라 서, 본 연구에서는 생체친화적 원소들로 구성된 $\mathrm{Ti}_{40} \mathrm{Zr}_{10} \mathrm{Cu}_{36} \mathrm{Pd}_{14}$ 합금을 선택하여 화학조성의 변화 없이 단순히 냉각속도를 변화시킴으로써 복합재화를 통해 연성을 부여하고자 하였 


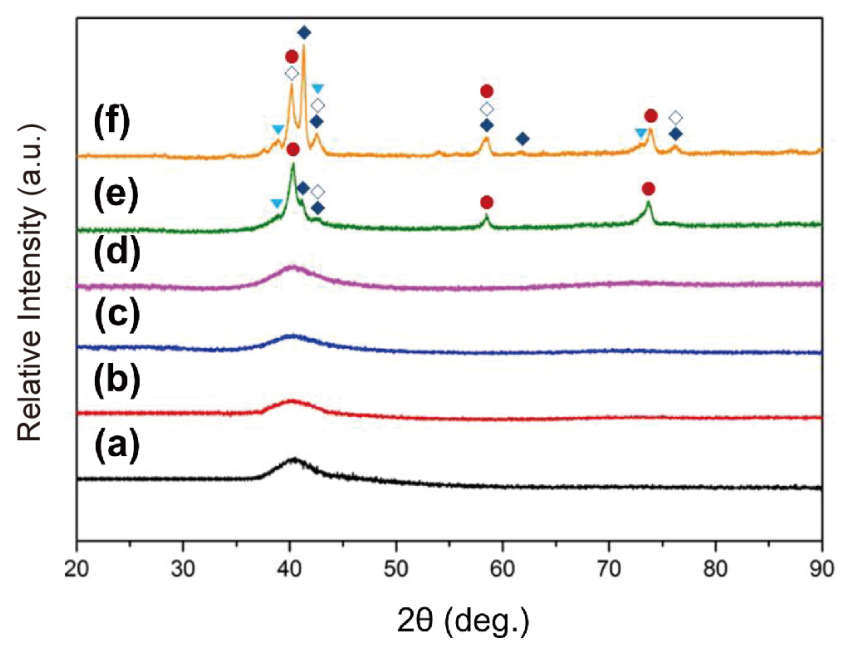

Fig. 1. X-ray diffraction patterns of $\mathrm{Ti}_{40} \mathrm{Zr}_{10} \mathrm{Cu}_{36} \mathrm{Pd}_{14}$ rods with a diameter of (a) $2 \mathrm{~mm}$, (b) $3 \mathrm{~mm}$, (c) $4 \mathrm{~mm}$, (d) $5 \mathrm{~mm}$, (e) $6 \mathrm{~mm}$, and (f) $7 \mathrm{~mm}\left(\bullet: \mathrm{B}_{2}, \diamond: \gamma-\mathrm{CuTi}, \diamond: \delta-\mathrm{CuTi}, \boldsymbol{\nabla}: \mathrm{C} 11 \mathrm{~b}\right)$.

다. 또한, 냉각속도의 변화가 미세조직 및 기계적 특성에 미 치는 영향을 자세히 살펴보았다.

\section{2. 실험방법}

플라즈마 아크 용해법(plasma arc melting, PAM)을 이용 하여 순도 $99.95 \%$ 이상인 $\mathrm{Ti}, \mathrm{Zr}, \mathrm{Cu}, \mathrm{Pd}$ 등을 고순도 아르곤 (순도 $99.999 \%$ 이상) 분위기 하에서 용해하였으며, 합금의 균질화를 위해 시편을 반전시켜가며 5 회 이상 재용해 하였 다. 이러한 과정을 통해 제조된 버튼 형태의 $\mathrm{Ti}_{40} \mathrm{Zr}_{10} \mathrm{Cu}_{36} \mathrm{Pd}_{14}$ 모합금을 석션 캐스팅법을 이용하여 다양한 직경 $(2 \sim 7 \mathrm{~mm})$ 의 봉상 시편을 제조하였다. 이때, 빠른 냉각속도의 봉상 시 편 제조를 위해 높이 $50 \mathrm{~mm}$ 의 무산소 동 도가니를 사용하였 다. 제조된 시편의 상분석을 위해 X-선 회절분석법(x-ray diffraction, XRD, Rigaku D/MAX2500/PC)을 이용하여 300 $\mathrm{mA}, 40 \mathrm{kV}$ 의 조건에서 $1.5 \% \mathrm{~min}$ 의 속도로 분석하였다. 전계 방사형 주사전자현미경(field emission scanning electron microscope, FE-SEM, JEOL JSM-7001F)을 이용하여 미세조 직을 관찰하였으며, 각 시편의 압축강도 및 소성변형률을 측 정하기 위해 만능시험기(universal testing machine, Hounsfield $\mathrm{H} 25 \mathrm{KT}$ )를 이용하여 $2 \times 10^{-4} \mathrm{~s}^{-1}$ 의 변형률로 일방향 압축시험 을 실시하였다. 이때, 봉상의 압축시편은 종횡비 2:1로 가공 하였으며, 직경이 $6 \mathrm{~mm}$ 인 경우에는 비교적 조직이 균질한 시편 내부에서 직육면체 $\left(2 \times 2 \times 4 \mathrm{~mm}^{3}\right)$ 형태로 시편을 채취하 였다.
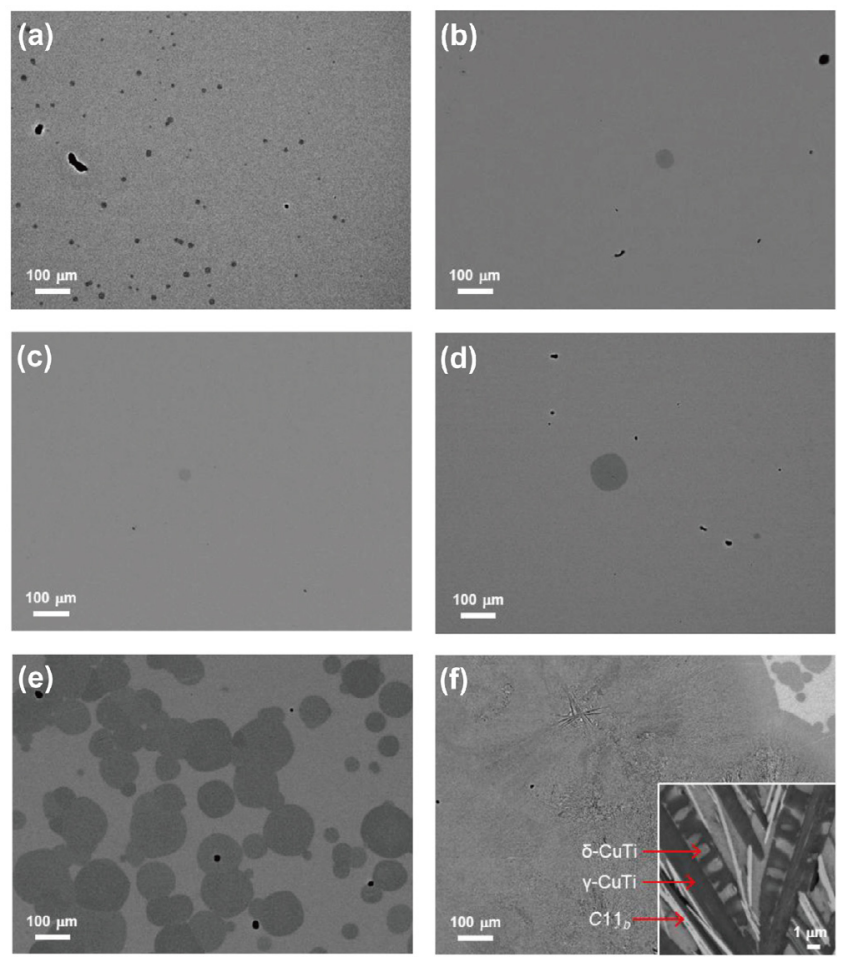

Fig. 2. SEM backscattered electron images of $\mathrm{Ti}_{40} \mathrm{Zr}_{10} \mathrm{Cu}_{36} \mathrm{Pd}_{14}$ rods with a diameter of (a) $2 \mathrm{~mm}$, (b) $3 \mathrm{~mm}$, (c) $4 \mathrm{~mm}$, (d) $5 \mathrm{~mm}$, (e) $6 \mathrm{~mm}$, and (f) $7 \mathrm{~mm}$. The inset of Fig. 2(f) exhibits the magnified image of Fig. 2(f).

\section{3. 결과 및 고찰}

$\mathrm{Li}$ 등의 연구결과에 따르면 [27], $\mathrm{Zr}$ 계 비정질 합금에서 냉 각속도는 직경의 자승에 반비례하는 것으로 알려져 있다. 따 라서 봉상의 직경을 조절함으로써 용탕의 냉각속도를 적절 히 변화시키고자 하였다. 그림 1(a)-(f)는 각각 직경 $2,3,4,5$, $6,7 \mathrm{~mm}$ 의 봉상으로 제조된 $\mathrm{Ti}_{40} \mathrm{Zr}_{10} \mathrm{Cu}_{36} \mathrm{Pd}_{14}$ 합금 시편에서 얻어진 회절패턴을 보여준다. 이때, 직경 $7 \mathrm{~mm}$ 인 경우에는 직경 $2 \mathrm{~mm}$ 인 경우보다 냉각속도가 10 배 이상 느린 것을 유 추할 수 있다. 냉각속도가 비교적 빠른 직경 2 5 mm 시편의 경우 전형적인 비정질 halo 패턴을 나타내었으며 (그림 1(a)-(d)), $6 \mathrm{~mm}$ 시편의 경우 halo 패턴과 결정 피크가 중첩되 어 나타났다 (그림 1(e)). $6 \mathrm{~mm}$ 시편에서 관찰되는 결정 피크 는 주로 B2상으로 이루어져 있는 것으로 여겨지며, $\gamma-\mathrm{CuTi}, \delta$ $-\mathrm{CuTi}, \mathrm{C} 11_{\mathrm{b}}$ 등의 다른 결정상들도 소량 생성된 것으로 보인 다. 한편 $7 \mathrm{~mm}$ 시편의 경우 B2 상의 분율은 줄어들고 대신 $\gamma$ $-\mathrm{CuTi}, \delta-\mathrm{CuTi}, \mathrm{C} 11_{\mathrm{b}}$ 등의 분율이 증가한 것으로 보인다 (그 림 1(f)). 따라서 본 합금의 비정질 임계직경은 약 $5 \mathrm{~mm}$ 로 추 
Table 1. Compressive mechanical properties of $\mathrm{Ti}_{40} \mathrm{Zr}_{10} \mathrm{Cu}_{36} \mathrm{Pd}_{14}$ rods with various diameters, where $\sigma_{y}$ and $\varepsilon_{p}$ are yield strength and plastic strain, respectively. Average values of $\sigma_{y}$ and $\varepsilon_{p}$ are listed.

\begin{tabular}{c|c|c}
\hline Rod diameter $(\mathrm{mm})$ & $\sigma_{y}(\mathrm{MPa})$ & $\varepsilon_{p}(\%)$ \\
\hline 2 & 1913 & 2.6 \\
\hline 3 & 1986 & 0.7 \\
\hline 4 & 1811 & 0.1 \\
\hline 5 & 1944 & 0.4 \\
\hline 6 & 1575 & 8.3 \\
\hline
\end{tabular}

산되며 이는 기존에 알려진 임계직경 $\left(\mathrm{D}_{\mathrm{c}}=6 \mathrm{~mm}\right.$ [11])과 비 슷한 것을 알 수 있다.

그림2(a)-(f)는 각 봉상 시편의 단면을 주사전자현미경으 로 촬영한 후방산란전자 (back scattered electron, BSE) 이미 지를 보여준다. 직경 $5 \mathrm{~mm}$ 까지의 시편에서는 중심과 표면 사이에 비교적 균질한 미세조직이 관찰되었는데, $\mathrm{X}$ 선 회절 패턴과는 달리 직경 2 5 mm 시편의 경우에도 수 수십 $\mu \mathrm{m}$ 크기를 갖는 B2상들이 극소량 생성된 것을 확인하였다 (그림 2(a)-(d)). 직경 $6 \mathrm{~mm}$ 이상의 시편에서는 냉각속도가 비교적 빠른 표면에서는 결정상의 분율이 중심부에 비해 적게 나타 났으며, 그림 2(e)와 2(f)는 결정상의 분율이 비교적 높은 시 편의 중심부를 촬영한 사진이다. 직경 $6 \mathrm{~mm}$ 의 경우에는 수 십 수백 $\mu \mathrm{m}$ 의 직경을 갖는 구형의(spherical) B2상이 다량 생성된 것을 확인하였으며, B2상의 부피분율은 약 $30 \%$ 로 시 편 중심부의 비정질 기지 내에 균일하게 분포하는 것으로 관 찰되었다 (그림 2(e)). 직경 $7 \mathrm{~mm}$ 시편의 경우에는 $\mathrm{X}$ 선 회절 패턴에서 확인한 바와 같이 대부분 결정화되어 비정질 영역 은 시편의 표면부을 제외하고는 거의 남아있지 않았으며 다 상(multi-phase)으로 구성된 수백 $\mu \mathrm{m}$ 크기의 결정립들이 관 찰되었다 (그림 2(f)). 그림 2(f)에 삽입된 이미지는 결정립 내 부를 확대한 것이며 $\mathrm{BSE}$ 모드에서 관찰결과 화학조성이 서 로 다른 세 개의 상으로 이루어졌음을 확인할 수 있었다. $\mathrm{SEM}-\mathrm{EDS}$ 를 이용하여 각 상의 성분분석을 실시한 결과, $\mathrm{BSE}$ 이미지 상 어두운 영역과 회색 영역은 $(\mathrm{Ti}, \mathrm{Zr}):(\mathrm{Cu}, \mathrm{Pd})=1: 1$ 의 정수비를 갖는 것으로 나타났으며 어두운 영역은 $\mathrm{Ti}$ 와 $\mathrm{Cu}$ 가 다량 포함된 반면, 회색 영역은 $\mathrm{Zr}$ 과 $\mathrm{Pd}$ 비율이 상대적으 로 높은 것으로 확인되었다. 이를 $\mathrm{XRD}$ 결과와 비교해보면 각각 $\gamma-\mathrm{CuTi}$ 와 $\delta-\mathrm{CuTi}$ 에 해당하는 것으로 짐작할 수 있다. 반면 흰색과 가까운 밝은 영역은 $(\mathrm{Ti}, \mathrm{Zr}):(\mathrm{Cu}, \mathrm{Pd})=1: 2$ 의 정수 비를 갖는 것으로 나타났으며, 이는 $\mathrm{XY}_{2}$ 타입의 $\mathrm{C} 11_{\mathrm{b}}$ 상과 구 성성분비가 일치한다. 흥미로운 점은 본 $\mathrm{Ti}_{40} \mathrm{Zr}_{10} \mathrm{Cu}_{36} \mathrm{Pd}_{14}$ 합 금 또한 $(\mathrm{Ti}, \mathrm{Zr}):(\mathrm{Cu}, \mathrm{Pd})=1: 1$ 의 정수비를 만족한다는 사실이

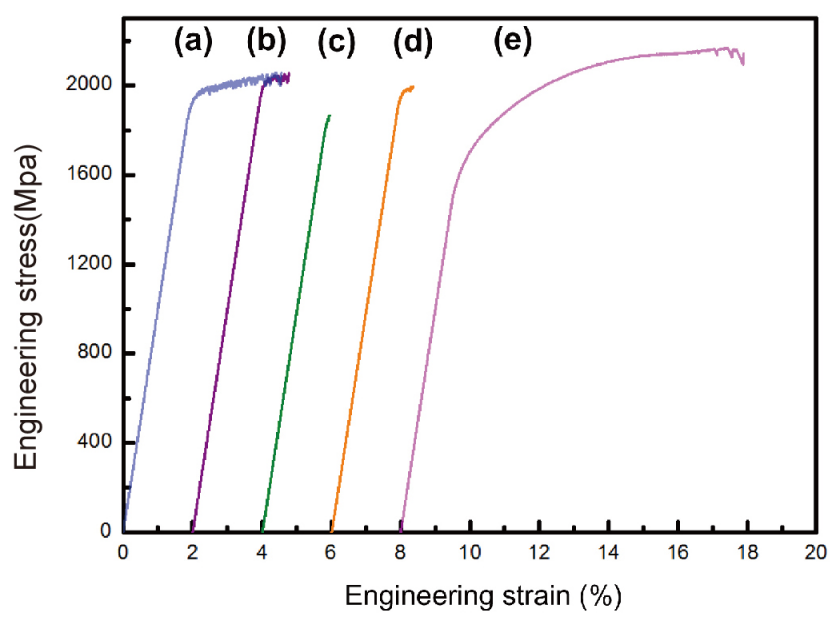

Fig. 3. Compressive engineering stress-strain curves at room temperature for $\mathrm{Ti}_{40} \mathrm{Zr}_{10} \mathrm{Cu}_{36} \mathrm{Pd}_{14}$ rods with a diameter of (a) 2 $\mathrm{mm}$, (b) $3 \mathrm{~mm}$, (c) $4 \mathrm{~mm}$, (d) $5 \mathrm{~mm}$, and (e) $6 \mathrm{~mm}$.

다. 비교적 느린 냉각속도 하에서 생성된 $\gamma-\mathrm{CuTi}$ 와 $\delta-\mathrm{CuTi}$ 상은 $(\mathrm{Ti}, \mathrm{Zr})$ 와 $(\mathrm{Cu}, \mathrm{Pd})$ 의 성분비가 모합금과 동일함에도 불 구하고 개개의 원소 함량은 모합금과 다른 반면, 비교적 빠른 냉각속도 하에서 생성된 B2상의 경우에는 각 원소의 함량이 모합금과 거의 일치한다는 점이다. 이러한 점으로 볼 때, B2 상의 경우 생성 초기단계에서 조성 재분배를 수반하지 않으 므로 조성 재분배가 요구되는 $\gamma-\mathrm{CuTi}$ 와 $\delta-\mathrm{CuTi}$ 상에 비해 활 성화에너지 장벽(activation energy barrier)이 낮기 때문에 [28] 빠른 냉각속도 하에서 비교적 쉽게 생성될 수 있는 것으 로 보인다.

냉각속도에 따른 상변화가 기계적 특성에 미치는 영향을 알아보기 위해 일방향 압축시험을 실시하였으며 시험을 통 해 얻어진 공칭응력-공칭변형률(engineering stress-strain curve) 곡선을 그림 3에 도시하였으며 그 결과를 표 1에 정리 하였다. 직경 $2 \mathrm{~mm}$ 시편의 경우(그림 3(a)) $2.6 \%$ 의 비교적 높 은 소성변형률(plastic strain)을 나타내었으나 직경 $3 \mathrm{~mm}$ 와 4 $\mathrm{mm}$ 시편의 경우(그림 $3(\mathrm{~b}),(\mathrm{c}))$ 에는 소성변형률이 각각 $0.7 \%, 0.1 \%$ 로 냉각속도 감소에 따른 뚜렷한 감소세를 나타 내었다. 하지만 직경 $5 \mathrm{~mm}$ 시편의 경우(그림 $3(\mathrm{~d})$ ) $0.4 \%$ 의 소 성변형률을 보였으며, 직경 $6 \mathrm{~mm}$ 시편의 경우(그림 $3(\mathrm{e})$ ) 약 $8 \%$ 의 뛰어난 소성변형률을 나타내는 등 냉각속도 감소에 따 라 이전과는 반대로 연성이 증가하는 경향을 나타내었다. 즉, 냉각속도에 따른 소성변형률 변화에 하나의 전이점이 존재 한다. 이러한 결과는 냉각속도의 변화가 야기하는 변수가 두 가지 이상이라는 점에 기인한다. 냉각속도가 비정질 기지 복 합재에 미치는 영향을 살펴보면 크게 두 가지를 고려할 수 있 

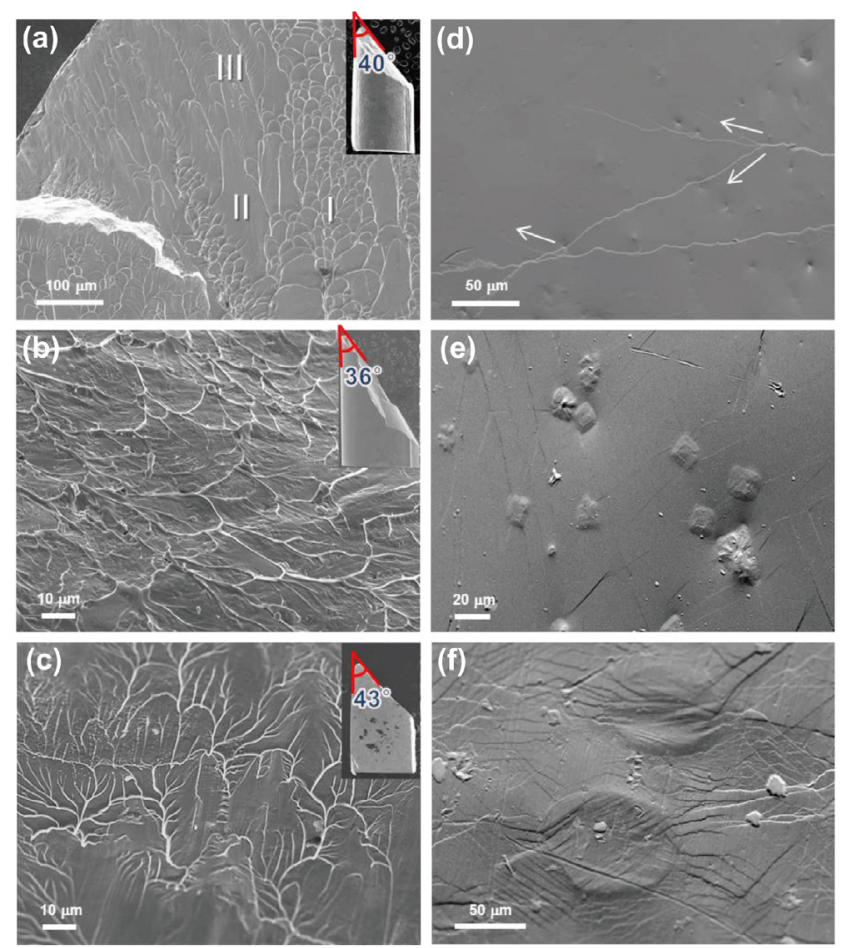

Fig. 4. Fracture surfaces of (a) $2 \mathrm{~mm}$, (b) $4 \mathrm{~mm}$, and (c) $6 \mathrm{~mm}$ specimens: (I) vein-like pattern, (II) intermittent smooth region, and (III) river-like pattern. The insets of Fig. 4(a)-(c) show the overall SEM images and shear fracture angles of failed samples after compression tests; Surface deformation morphologies of (d) $2 \mathrm{~mm}$, (e) $4 \mathrm{~mm}$, and (f) $6 \mathrm{~mm}$ specimens. The inserted arrows in Fig. 4(d) indicate branching of shear bands.

는데, 하나는 결정상의 종류와 부피분율의 변화이고 다른 하 나는 비정질 기지 내의 자유부피(free volume)의 변화이다. 자유부피는 급속응고 시 비정질 기지 내에 생성되며 절대온 도에서의 액체의 몰부피(molar volume)와 비교했을 때의 여 분의 부피를 의미한다 [29]. 이러한 Free volume은 전단 띠의 생성과 전파의 분산에 도움을 줄 뿐 아니라 크랙 팁(crack tip) 주변의 응력 완화(stress relaxation)에 기여함으로써 비정 질 기지에 연성을 부여한다고 알려져 있다 [30]. 자유부피의 양은 냉각속도가 빠를수록 증가하는 경향이 있으므로 냉각 속도가 빠를수록 자유부피의 양이 증가하게 되어 연성이 증 가하게 된다 [30-34]. 비정질 기지 복합재의 경우 결정상의 특성, 크기, 분포, 분율 등에 영향을 받는 것으로 알려져 있는 데 [35], 비정질 기지에 비해 강성(stiffness)이 낮은 결정상의 경우에 전단 띠의 생성 및 전단 띠의 전파를 차단하는데 관여 할 수 있다. 또한 연성을 갖는 결정상의 분율이 높을수록 복 합재의 연성이 증가되며 결정상의 크기가 $1 \mu \mathrm{m} \sim 1 \mathrm{~mm}$ 의 범 위에서 클수록 전단 띠의 전파를 지연시키는데 유리한 것으
로 알려져 있다 [35]. 본 합금의 경우에는 직경 $6 \mathrm{~mm}$ 시편에 서 수십 수백 $\mu \mathrm{m}$ 의 직경을 가지며 약 $30 \%$ 의 부피분율을 갖 는 구형의 B2상이 비교적 균일하게 분포함으로써 소성변형 률이 급격히 증가한 것으로 보인다 (그림 3(e)). B2상의 경우 경화상(hard phase)로 알려져 있으나 비정질 기지에 비해서 는 낮은 강성을 가지기 때문에 전단 띠의 생성과 전파에 관여 하는 것으로 여겨진다. 또한 직경 $5 \mathrm{~mm}$ 시편의 경우 직경 4 $\mathrm{mm}$ 시편에 비해 약간의 연성을 갖는 것으로 나타났는데, 이 는 $5 \mathrm{~mm}$ 시편에서 생성된 $\mathrm{B} 2$ 상의 크기가 $4 \mathrm{~mm}$ 이하 시편들 에 비해 비교적 커짐으로써 전단 띠와 상호작용이 활성화 된 것으로 판단된다 (그림 2(d)). 표 1 을 보면 각 시편의 항복강 도(yield strength)가 나타나있는데 직경 2 5 mm 시편의 경우 $\mathrm{B} 2$ 상의 부피분율에 큰 차이가 없으므로 약 $1900 \mathrm{MPa}$ 정도의 비슷한 항복강도 값을 나타내는 반면, 직경 $6 \mathrm{~mm}$ 시편의 경 우 비정질 기지에 비해 낮은 강도를 갖는 B2상의 부피분율이 높으므로 항복강도 값(1575 MPa)이 큰 폭으로 감소한 것을 볼 수 있다.

그림4(a)-(c)는 직경 $2 \mathrm{~mm}, 4 \mathrm{~mm}, 6 \mathrm{~mm}$ 의 봉상 시편을 압 축시험 후 파단면(fracture surface)을 주사전사현미경으로 관 찰한 사진이다. 그림 4(a)-(c)에서 볼 수 있는 바와 같이 각 시 편의 파단 형상(fracture morphology)이 판이하게 다른 것을 확인할 수 있다. 먼저 직경 $2 \mathrm{~mm}$ 시편의 경우 그림 4(a)에 표 시한 바와 같이 vein-like pattern(I), intermittent smooth region(II), river-like pattern(III) 등이 혼합된 파단 형상이 관 찰되었다. 반면, 직경 $4 \mathrm{~mm}$ 와 $6 \mathrm{~mm}$ 시편의 경우에는 파단면 이 주로 smooth region(그림4 (b))과 river-like pattern(그림 4(c))으로 각각 이루어져 있는 것으로 관찰되었다. Jiang 등에 따르면 [36], vein-like pattern은 전단 띠가 빠르게 전파될 때 주로 생성되는 반면, river-like pattern은 2차(secondary) 또는 3 차(tertiary) 전단 띠의 작용에 의해 생성되는 것으로 보고되 었다. 전단 띠가 많이 생성되고 이러한 전단 띠의 전파 시 분 산(branching)이 활발히 일어날수록 가소성(plasticity)이 증 가하게 된다. 따라서 river-like pattern 영역이 많이 관찰된다 는 것은 그만큼 합금 시편에 연성이 부여되었음을 의미한다. 본 연구에서도 마찬가지로 표 1에서 볼 수 있는 바와 같이, 파 단면에 river-like pattern 영역이 많이 생성된 직경 $6 \mathrm{~mm}$ 시편 에서 가장 높은 소성변형률을 나타내었으며 주로 매끄러운 파단면을 보인 직경 $4 \mathrm{~mm}$ 시편에서는 가장 낮은 소성변형률 을 나타내는 등 기존 결과와 잘 일치한다. 직경 $2 \mathrm{~mm}$ 시편의 경우에는 세 가지 패턴이 고루 분산되어 있으므로 직경 4 $\mathrm{mm}$ 보다는 높고 직경 $6 \mathrm{~mm}$ 보다는 낮은 소성변형률을 나타 
낸 것을 알 수 있다. 또한, 전단 파단 각도(shear fracture angle)에 의해서도 가소성 정도를 판단할 수 있는데, 전단 파 단 각도가 클수록 일반적으로 우수한 가소성을 지닌 것으로 알려져 있다 [37]. 이는 높은 압축 응력이 가해질 때 1차 (primary) 전단 띠가 2차 전단 띠들과 충돌하면서 전단 파단 면(shear fracture plane)이 시편의 수평 방향으로 회전하기 때 문이다 [37]. 그림 4(a)-(c)에 삽입된 파단 후 압축시편의 전단 파단 각도를 살펴보면 $6 \mathrm{~mm}, 2 \mathrm{~mm}, 4 \mathrm{~mm}$ 순으로 높은 것을 알 수 있는데, 이는 기존 결과와 잘 일치하는 것을 알 수 있다. 결정상과 전단 띠의 상호작용을 알아보기 위해 시편 표면의 변형 형상(surface deformation morphology)을 추가적으로 관 찰하였다(그림 4(d)-(f)). 먼저 냉각속도가 비교적 빠른 직경 2 $\mathrm{mm}$ 시편의 경우(그림 4(d)), 화살표로 표시된 바와 같이 전단 띠의 분산이 비교적 잘 이루어졌음을 확인할 수 있는데, 이는 $\mathrm{B} 2$ 상과의 상호작용이라기보다는 빠른 냉각속도로 인해 비정 질 기지 내에 다량 생성된 자유부피와의 상호작용에 의한 것 으로 여겨진다. 직경 $4 \mathrm{~mm}$ 시편의 경우(그림 4(e)), 표면에 $10 ~ 20 \mu \mathrm{m}$ 크기를 갖는 B2상들이 관찰되었으나 전단 띠와의 상호작용은 그리 활발하지 못한 것으로 보인다. 반면, 직경 6 $\mathrm{mm}$ 시편의 경우(그림 4(f)), 표면에 약 50 100 $\mu \mathrm{m}$ 크기의 B2 상들이 관찰되었으며 $\mathrm{B} 2$ 상 주변에 전단 띠의 생성, 흡수, 분 산 등이 매우 활발히 일어난 것을 관찰할 수 있었다. 따라서 $\mathrm{B} 2$ 상의 크기가 클수록 전단 띠와의 상호작용이 더욱 증대되 며, 이로 인해 소성변형률이 증가하는 것을 알 수 있다.

\section{4. 결 론}

본 연구를 통해 $\mathrm{Ti}_{40} \mathrm{Zr}_{10} \mathrm{Cu}_{36} \mathrm{Pd}_{14}$ 합금의 경우 냉각속도와 기계적 특성 간 밀접한 상관관계가 있음을 확인하였다. 이는 합금의 응고 조직이 냉각속도에 큰 영향을 받기 때문이며, 냉 각속도에 따라 결정상의 종류, 크기, 분율 등이 결정될 뿐 아 니라 비정질 기지 내의 자유부피 양이 변화한다는 사실에 기 인한다. 냉각속도가 비교적 빠른 직경 2 4 mm 시편의 경우, 생성된 결정상의 부피 분율이 매우 적었기 때문에 냉각속도 가 빠른 순 $(2 \mathrm{~mm}>3 \mathrm{~mm}>4 \mathrm{~mm})$ 으로 높은 소성변형률을 나 타내었다. 이는 냉각속도가 빠를수록 생성되는 자유부피 양 이 증가하기 때문이다. 반면, 직경 $5 \mathrm{~mm}$ 이상의 시편에서는 $\mathrm{B} 2$ 상의 크기 및 분율이 증가함에 따라 소성변형률이 증가하 였는데, 이때 복합재의 연성은 결정상(B2상)의 부피 분율에 의존하기 때문이다. 직경 $6 \mathrm{~mm}$ 시편에서 연성을 갖는 $\mathrm{B} 2$ 상 이 다량 생성되었으며 이로 인해 복합재의 연성이 크게 증가
하였다. 하지만 직경 $7 \mathrm{~mm}$ 시편에서는 비교적 느린 냉각속 도로 인하여 조성 재분배가 발생하게 되며, 이 과정에서 시편 전반에 다상 $\left(\gamma-\mathrm{CuTi}, \delta\right.$-CuTi, $\left.\mathrm{C} 11_{\mathrm{b}}\right)$ 이 생성되었다. 따라서 $\mathrm{Ti}_{40} \mathrm{Zr}_{10} \mathrm{Cu}_{36} \mathrm{Pd}_{14}$ 합금의 경우, 냉각속도가 미세조직 및 기계 적 특성을 결정하는 핵심 요소라 하겠다.

\section{감사의 글}

본 연구는 정부(산업통상자원부)의 재원으로 산업융합기 반구축사업(과제번호: N0000846) 지원을 받아 수행되었으 며, 이에 감사드립니다.

\section{REFERENCES}

1. M. Niinomi, Metall. Mater. Trans. A 33, 447 (2002).

2. K. R. Lim, J. H. Na, J. M. Park, W. T. Kim, and D. H. Kim, J. Mater. Res. 25, 2183 (2010).

3. T. Zhang and A. Inoue, Mater. Trans. 10, 1001 (1998).

4. A. Inoue, N. Nishiyama, K. Amiya, T. Zhang, and T. Masumoto, Mater. Lett. 19, 131 (1994).

5. T. Zhang, A. Inoue, and T. Masumoto, Mater. Sci. Eng. A 181, 1423 (1994).

6. G. Duan, A. Wiest, M. L. Lind, A. Kahl, and W. L. Johnson, Scripta Mater. 58, 465 (2008).

7. C. Ma, S. Ishihara, H. Soejima, N. Nishiyama, and A. Inoue, Mater. Trans. 45, 1802 (2004).

8. T. Zhang and A. Inoue, Mater. Sci. Eng. A 304, 771 (2001).

9. T. Zhang and A. Inoue, Mater Trans. 40, 301 (1999).

10. H. Men, S. Pang, A. Inoue, and T. Zhang, Mater. Trans. 10, 2218 (2005).

11. S. L. Zhu, X. M. Wang, F. X. Qin, M. Yoshimura and A. Inoue, Mater. Trans. 48, 2445 (2007).

12. R. Maaß, D. Klaumunzer, and J.F. Loffler, Acta Mater. 59, 3205 (2011).

13. M. R. Lee, K. W. Park, H. J. Sa, and J. C. Lee, J. Kor. Inst. Met. \& Mater. 45, 687 (2009).

14. M. W. Lee, H. J. Shin, S. H. Hong, J. T. Kim, H. Choi-Yim, Y. Seo, W. H. Lee, P. Yu, M. Qian, J. K. Lee, and K. B. Kim, Met. Mater. Int. 20, 1 (2014).

15. S. W. Lee, C. M. Lee, S. W. Chae, Y. C. Kim, and J. C. Lee, J. Kor. Inst. Met. \& Mater. 43, 337 (2005).

16. F. Szuecs, C. P. Kim, and W. L. Johnson, Acta Mater. 49, 1507 (2001).

17. F. Jiang, D. H. Zhang, L. C Zhang, Z. B. Zhang, L. He, J. Sun, and Z. F. Zhang, Mater. Sci. Eng. A 467, 139 (2007).

18. C. Fan, R. T. Ott, and T. C. Hufnagel, Appl. Phys. Lett. 81, 6 (2002).

19. P. Gargarella, S. Pauly, M. Samadi Khoshkhoo, U. Kuhn, and J. Eckert, Acta Mater. 64, 259 (2014).

20. C. C. Hays, C. P. Kim, and W. L. Johnson, Phys. Rev. 
Lett. 84, 13 (2000).

21. J. B. Qiang, W. Zhang, G. Q. Xie, and A. Inoue, Appl. Phys. Lett. 90, 231907 (2007).

22. F. X. Qin, X. M. Wang, G. Q. Xie, and A. Inoue, Intermetallics 16, 1026 (2008).

23. F. X. Qin, X. M. Wang, and A. Inoue, Mater. Trans. 48, 2390 (2007).

24. U. Kühn, J. Eckert, N. Mattern, and L. Schultz, Appl. Phys. Lett. 80, 2478 (2002).

25. Y. C. Kim, K. B. Kim, E. Fleury, J. C. Lee, and D. H. Kim, J. Kor. Inst. Met. \& Mater. 43, 12 (2005).

26. F. X. Qin, X. M. Wang, and A. Inoue, Intermetallics 15, 1337 (2007).

27. C. Li, S. Kou, Y. Zhao, G. Liu, and Y. Ding, Prog. Nat. Sci. 22, 21 (2012).

28. H. Sun and K. M. Flores, Intermetallics 19, 1538 (2011).

29. P. Ramachandrarao, B. Cantor, and R. W. Cahn, J. Mater. Sci. 12, 2488 (1977).
30. L. Y. Chen, A. D. Setyawan, H. Kato, A. Inoue, G. Q. Zhang, J. Saida, X. D. Wang, Q. P. Caoa, and J. Z. Jiang, Scripta Mater. 59, 75 (2008).

31. F. Sqaepen, Acta Metall. Mater. 25, 407 (1977).

32. P. S. Steif, F. Spaepen, and J. W. Hutchinson, Acta Metall. 30, 447 (1982).

33. J. Shen, Y. J. Huang, and J. F. Sun, J. Mater. Res. 22, 11 (2007).

34. S. H. Joo, D. H. Pi, J. Guo, H. Kato, S. H. Lee and H. S. Kim, Met. Mater. Int. 22, 3 (2016).

35. D. C. Hofmann, J. Y. Suh, A. Wiest, G. Duan, M. L. Lind, M. D. Demetriou, and W. L. Johnson, Nature 451, 1085 (2008).

36. F. Jiang, D. H. Zhang, L. C. Zhang, Z. B. Zhang, L. Hea, J. Suna, and Z. F. Zhang, Mater. Sci. Eng. A 467, 139 (2007).

37. Z. F. Zhang, G. He, H. Zhang, and J. Eckert, Scripta Mater. 52, 945 (2005). 